\title{
EFFECTIVE FOREIGN AND DOMESTIC STANDARD PROGRAMS USED IN TEACHING ENGLISH
}

\author{
Gulden Akbayeva ${ }^{1}$, Saida Satimova ${ }^{2}$ \\ ${ }^{1}$ E.A. Buketov Karaganda University, Karaganda, Kazakhstan \\ ${ }^{2}$ E.A. Buketov Karaganda University, Karaganda, Kazakhstan \\ ORCID iD: 0000-0002-0314-0944
}

\begin{abstract}
In the modern world, the study of foreign languages is very relevant. Because thanks to this, a person acquires many opportunities and a chance to succeed. This is especially true for English language skills. Which is not only one of the necessities for a modern, successful person, but also one of the factors of competitiveness and the quality of education of the whole country. Therefore, at the present stage, special attention is paid to teaching English. And as practice shows, one of the most effective ways to learn a foreign language is the use of various standard programs in teaching English which were analyzed. At the same time the results of experimental and practical work were presented.
\end{abstract}

\section{INTRODUCTION}

The world is changing rapidly, relations between people, various human communities, countries are changing, people's lives in states are changing, but its success, the well-being of people largely depends on public consciousness, therefore, on the upbringing of a person. A new generation with a high level of awareness is the task of society. In recent decades, the study of foreign languages has aroused increased interest. At the same time, the increasing role of foreign languages in influencing people's consciousness and activity is noted. It should also be borne in mind that knowledge of languages can play an important role and give some advantages in personal and professional communication. As a result of global globalization and integration, there has been a rapid growth of intercultural contacts in all spheres of our life: a wide variety of situations of intercultural communication have appeared, such as studying at school and university for exchange, internships for scientists, international conferences, joint ventures, tourist trips, exhibitions, etc. Thus, proficiency in a foreign language is one of the conditions for successful adaptation in the social space.

Knowledge of a foreign language is an integral part of educating successful people. Therefore, in the personal and professional development of a modern person, it is impossible to do without knowledge of foreign languages. The ability to communicate with representatives of different cultures contributes to the development of horizons and allows you to move up the career ladder, make useful acquaintances. Today, employers welcome knowledge of foreign languages. English is the most in demand today. English is the language of international communication. It is the language of navigation, aviation, literature, education, modern music, international sports, tourism and programming. $75 \%$ of the world's correspondence is conducted in English, $60 \%$ of radio stations broadcast in English, more than half of the world's magazines are published in English and 80\% of the information is stored in this language. English is the most widely spoken language in the world today: more than 400 million people speak it as their native language, but the number of people speaking it as a foreign language is three times more [Kolesnik \& Volkova, 2017].

It is difficult to overestimate the importance of knowledge of a foreign language. Most modern means of communication are aimed at people who somehow speak the language. For example, in everyday life we often encounter the English language - the Internet, music, annotations to foreign goods, the description of which in Russian or in a foreign language is often scarce and does not always meet the needs of the consumer, etc. Now the influence of information technology on the working environment is very great, where knowledge of foreign languages helps to build a full and competent 
work. Since the twentieth century, the role of English as one of the indicators of a person's success and education has increased, which immediately leads to the fact that in most educational institutions of our country it is taught more intensively and deeply.

The modern education system is developing in the conditions of increasing globalization of economic and socio-cultural processes, integration into various spheres of activity. A universally recognized requirement of the time is the preparation of a person who has a certain set of social, cultural and communicative qualities and is able to act in an ever-changing reality. In this regard, an important role in the education of modern children is played by the study of foreign languages as an important means of intercultural interaction and general personal development.

Teaching foreign languages occupies a significant place in the modern world, new social trends have led to the fact that languages are necessary not only for travel, but also for study and work. The main purpose of teaching a foreign language is the formation of communicative competence through familiarization with other traditions and participation in the dialogue of cultures [Sorokina, 2016]. Learning to understand the processes taking place, living in this multilingual world, will naturally help the new generation of knowledge of languages. In acquiring this knowledge, the teacher plays a primary role.

The thinking of a modern person is not limited to the borders of a city or a country - we think much more broadly and perceive the world in a more holistic way. As a result, the role of education in general is changing, new teaching methods are emerging. But the teacher and the student remain participants in the educational process to this day. The modern paradigm of education involves rethinking approaches to teaching methods, tasks of the educational system. Today, learning is, first of all, a willingness to learn new things, improve already acquired skills and update them. Teachers must adapt to the challenges they face in an ever-changing education system. Even in the era of posttruth and uncertainty, teachers need to believe in their knowledge and skills and constantly improve them. Continuing education is important not only for the student, but also for the teacher. Perhaps this is even more of a priority for a teacher, because it is necessary to adapt to changing realities, adapt to requirements and follow trends in order to be in demand in the labor market. At the moment, there are the most effective English language learning programs. And many of them are used as language learning programs that are used abroad, are presented in Table 1.

Table 1. Programs for teaching English

\begin{tabular}{|l|l|}
\hline Program & Description \\
\hline $\begin{array}{l}\text { Professor Higgins } \\
\text { is an interactive } \\
\text { self-taught } \\
\text { English language }\end{array}$ & $\begin{array}{l}\text { It is rightfully considered one of the best self-taught English. This program } \\
\text { for learning English words on a computer has two main sections, which are } \\
\text { devoted to oral and written English. }\end{array}$ \\
\hline $\begin{array}{l}\text { English } \\
\text { Discoveries }\end{array}$ & $\begin{array}{l}\text { English Discoveries is designed for beginners and for those who have } \\
\text { already studied English before. }\end{array}$ \\
\hline $\begin{array}{l}\text { Longman } \\
\text { Кollection } \\
\text { Lоллекция }\end{array}$ & $\begin{array}{l}\text { A well-known program for English language training, which is based on the } \\
\text { NATONCollection. The program includes a lot of exercises for the } \\
\text { development of written and oral speech, vocabulary development, grammar, } \\
\text { etc. }\end{array}$ \\
\hline English 9.0 & $\begin{array}{l}\text { English is considered here in everyday situations, which is very useful for } \\
\text { beginners. The American version of English is also studied in this program. }\end{array}$ \\
\hline
\end{tabular}




\begin{tabular}{|l|l|}
\hline $\begin{array}{l}\text { BX Language } \\
\text { acquisition }\end{array}$ & $\begin{array}{l}\text { The program is based on the methodology of Herman Ebbinghaus and } \\
\text { Sebastian Leitner. Moreover, with the help of it, you can learn not only } \\
\text { English words, but also expand the dictionary in 46 other languages. }\end{array}$ \\
\hline $\begin{array}{l}\text { English Grammar } \\
\text { in Use Activities }\end{array}$ & $\begin{array}{l}\text { The official Cambridge University Press app that focuses on grammar } \\
\text { development. }\end{array}$ \\
\hline Language Bridge & $\begin{array}{l}\text { The whole teaching method consists in "synchronous multiple repetition" } \\
\text { based not only on words, but also images. }\end{array}$ \\
\hline $\begin{array}{l}\text { English Trainer } \\
4800\end{array}$ & $\begin{array}{l}\text { The program provides you with suggestions for translation, after which an } \\
\text { assessment of the work done is given. The application is of particular interest } \\
\text { for translators, as well as for anyone who needs the practice of translating } \\
\text { English texts. }\end{array}$ \\
\hline Rosetta Stone & $\begin{array}{l}\text { The application offers to learn English on an intuitive level with the help of } \\
\text { associations. Moreover, the software is great for children. With the help of } \\
\text { Rosetta Stone, you will train not only written speech, but also oral. }\end{array}$ \\
\hline Memrise & $\begin{array}{l}\text { In 2017, this application was recognized as the best. It offers a variety of } \\
\text { games and programs for learning English that are suitable for both children } \\
\text { and adults. The program itself is presented in the form of a huge space } \\
\text { adventure, during which you learn English words and grammar. }\end{array}$ \\
\hline
\end{tabular}

Historically, the language situation in Kazakhstan has led to the bilingualism of a significant part of the population. The other day, the Minister of Culture and Sports of the Republic of Kazakhstan Arystanbek Mukhamediuly said that more than $80 \%$ of Kazakhs speak the Kazakh language. At the same time, according to him, only $22 \%$ of the population speak three languages. These data are confirmed by the world's largest English proficiency rating, the EF English Proficiency Index. In it, Kazakhstan ranks 67th out of 80 countries, which is assessed as a "very low level of language proficiency". This indicator is equivalent to the A2 or Pre-Intermediate level. It is assumed that the training of the three target languages will be conducted according to the CEFR model, as well as using the communicative and methodological approach described above. At the same time, the most suitable method is CLIL - comprehensive teaching of subjects and languages. For teachers who want to learn how to use interactive electronic resources in the classroom, the British Council, together with JSC NCPC "Orleu", has developed a guide "Digital resources for students in grades 111". The Teaching English website has articles, videos, a selection of online courses and webinars for advanced training. Free lesson plans, educational materials, educational articles, and classroom assignments are available on the site. The British Council also offers various online courses for primary and secondary school teachers, seminars on teaching methods and other topics. In addition, the British Council offers a wide range of useful learning resources. Another effective platform for learning a foreign language is "Edustream Kazakhstan". And there are also other programs for teaching English, which are used in Kazakhstan (Table 2).

Table 2. Programs for teaching English

\begin{tabular}{|l|l|}
\hline Program & Description \\
\hline Wlingua & $\begin{array}{l}\text { This program is the best learning tool. The program will support both a } \\
\text { group of beginners and another group continuing their studies. After } \\
\text { downloading, take the test and determine your level. You can also include }\end{array}$ \\
\hline
\end{tabular}




\begin{tabular}{|l|l|}
\hline & $\begin{array}{l}\text { in the curriculum what lesson you are studying, what rules you should pay } \\
\text { attention to. You can also choose between British and American accents. } \\
\text { There are 600 lessons in the Wlingua program in total. If you can do these } \\
\text { lessons endlessly, you will achieve excellent results. }\end{array}$ \\
\hline $\begin{array}{l}\text { Phrasal Verbs for \& Exams } \\
\text { With these programs, you can improve your English language skills. The } \\
\text { fact is that this programmer pays more attention to phrasal verbs (phrasal } \\
\text { verbs), which are more often used in English than in grammar. A model of } \\
\text { their application is also proposed. However, the free version only explains } \\
\text { the basic level. Well, the rest of the lessons will have to be bought in order } \\
\text { to learn. }\end{array}$ \\
\hline LingQ & $\begin{array}{l}\text { This program is an indispensable assistant for those who want to work on } \\
\text { reading, listening and translating. Thousands of tasks are devoted to } \\
\text { vocabulary and teachers. Each word can be marked as known or unknown. } \\
\text { To find a translation of unfamiliar words, click "Yandex. He will go to the } \\
\text { interpreter." In addition, you can get information about the studied words, } \\
\text { completed tasks. }\end{array}$ \\
\hline HnakeLang & $\begin{array}{l}\text { When you say "play", you forget everything and can't find time to learn } \\
\text { English, this program allows you to do two things at the same time. In the } \\
\text { process of completing test tasks, you move the snake forward. To get a high } \\
\text { score, you must have time to answer in a certain time. }\end{array}$ \\
$\begin{array}{l}\text { This program is an indispensable assistant for those who prefer to ask } \\
\text { you can communicate with native speakers, that is, with foreigners. By } \\
\text { exchanging information with them via messages, you can improve your } \\
\text { conversational skills with the help of sound. }\end{array}$ \\
\hline
\end{tabular}

In the context of distance learning in English, explaining and increasing students' interest in the subject in their native language has become a serious problem. I want to say that when solving this problem, I searched a lot and found a significant solution. Given the current interest of students in computer games, it became clear to me for the first time that studying EMC subjects in English requires the use of effective platforms and programs. Platforms for learning English - duolingo.com, lingualeo.com , Dictionary.cambridge.org. With this platform, you can learn English from beginner to advanced level [Yeskali, 2020]. However, it seems difficult to recruit one of the most effective programs.

\section{CONCLUSIONS}

To identify the most effective standard programs used in teaching a foreign language, we conducted an online survey among students and adults who are currently teaching English. They also offered to get acquainted with these programs and platforms. 20 people took part in the survey. To do this, we asked several questions for the respondents. The questions were as follows:

1. Do you use English language learning programs from our list?

2. How often do you use these programs?

3. Which of the above do you consider the most effective? 
The results were as follows: 16 of the respondents had used these programs before, 4 of them use other programs and most of them study textbooks. The frequency of use of these programs is varied: 1 time per week - 1 person

2 times a week - 6 people

3 times a week - 10 people

every day - 3 people

The most effective program is considered: Memrise, Rosetta Stone, Wlingua. The results are noticeable, however, they note that although grammar has improved, some have problems with noncontractual practice (figure 1, figure 2).

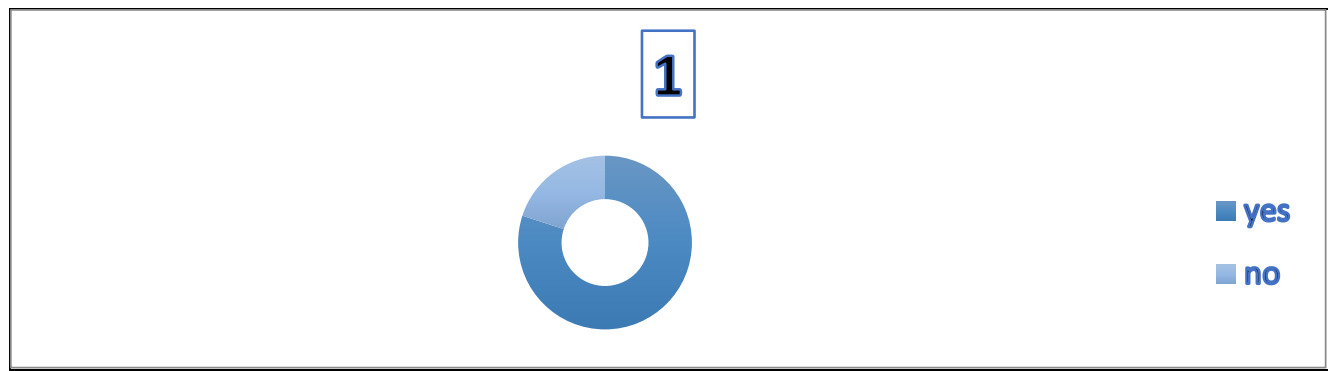

Figure 1. Diagram
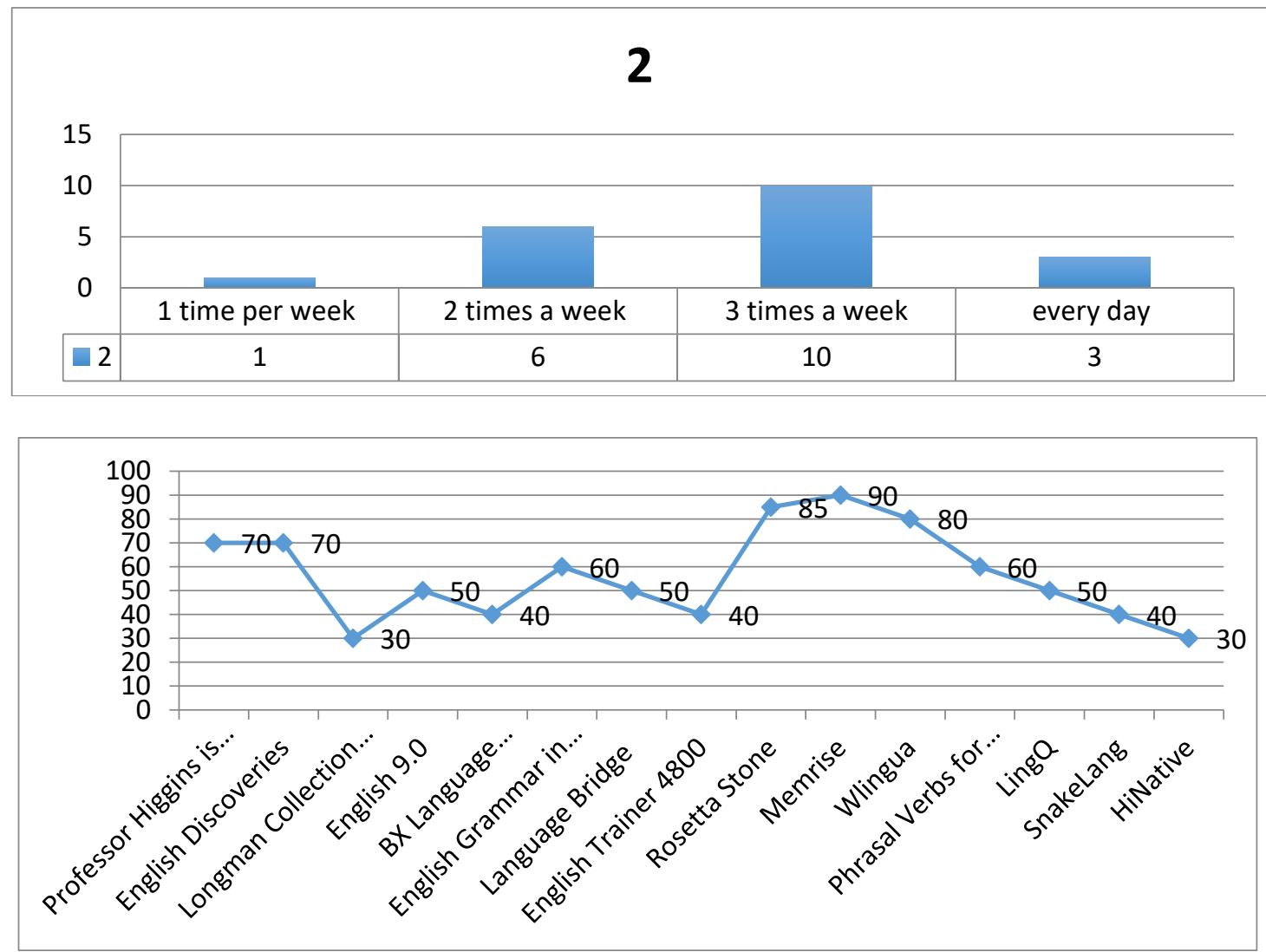

Figure 2. Diagrams

Secondary use platforms:

Learningapps.com,

Educandy.com,

edpuzzle.com,

www.classcraft.com,

padlet.com,

www.memrise.com,

b.socrative.com, 
jeopardylabs.com.

The platform can transmit information in English across all CIV disciplines using various methods and techniques. Schools with multilingual education should teach students who are proficient in the language. Currently, the teaching of a general subject in three languages is receiving great support. It was necessary. In many schools of the country, subjects are taught in English. Based on all this, I consider it important to teach subject teachers to use effective distance learning methods. These terms are translated into Kazakh by transliteration. The structure and methodological content of each IR is as follows: Hotlist (list by topic); a set of multimedia resources Multimedia scrapbook (multimedia paper). Scrapbook ; Treasure hunt (treasure hunt)- Hotlist; Subject sampler; Webquest, etc.

It can be argued that all modern programs that are effective in teaching English have as their main goal to increase the activity of students, their independent activity in obtaining knowledge, truth, because the truth obtained by their own efforts has great cognitive value. The most important thing is the satisfaction with the lessons, which positively affects both the motives and teaching methods, as well as the tendency of students to communicate with the teacher, classmates and create useful relationships during the lesson.

\section{REFERENCES:}

Kolesnik A.A. (2017) The relevance of foreign language proficiency in the modern world // A.A. Kolesnik, S. A. Volkova. - Text: direct // Young scientist. № 3, 562-564.

Shagataeva Z.Zh. (2008) On the relevance of learning foreign languages in modern Pedagogical Science and Practice, 130-135.

Sorokina N.I. (2016) Communicative competence in professional training of a specialist // Agrarian education and science. № 2. 62.

The best programs for learning English [Learning English], Yandex Zen [https://www.toptenreviews.com/best-learn-english-software].

Yeskali T. (2020) Agylshyn tilin uyrenuge arnalgan 5 bagdarlama. [5 programs for learning English], [ massaget.kz] 